\title{
Roundtable World Editors
}

\section{A Conversation with Leonora Djament (Buenos Aires/Eterna Cadencia), Gustavo Guerrero (Paris/Gallimard), Isabelle Gugnon (Paris/Translator), Michi Strausfeld (Berlin/Editor), and Frank Wegner (Berlin/Suhrkamp)}

Hannover, July 1, 2019

Participants: Leonora Djament (LD), Gustavo Guerrero (GG), Isabelle Gugnon (IG), Michi Strausfeld (MS), Frank Wegner (FW), Público (P)

GG: Muchas gracias a ustedes cuatro por haber aceptado estar esta noche con nosotros. Voy a comenzar con una pregunta general para todos. Quisiera que comenzáramos a hablar un poco del presente y luego, si quieren, vamos un poco más atrás en el tiempo. Voy a dar tres datos que me resultan inquietantes: hace una semana, el 22 de junio del 2019, el periódico Le Monde publicó en Francia un suplemento con las 100 novelas que, según sus redactores, han marcado las siete décadas de existencia del periódico, desde 1944 hasta 2019. Esta panorámica elaborada por los actuales responsables de las páginas de cultura de Le Monde es una perspectiva, pues, sobre prácticamente 75 años de literatura. Curiosamente dentro de la lista de 100 autores solo aparecieron tres novelas latinoamericanas: 2666 de Bolaño, El entenado de Saer y Cien años de soledad de Gabriel García Márquez. Mi comentario en Twitter a esa lista fue el siguiente: “como si el boom nunca hubiera ocurrido". Porque pareciera que en la perspectiva francesa actual de los años 60, 70, 80, sobreviven solo tres novelas latinoamericanas dispersas en el tiempo, como si el momento del boom nunca hubiese existido.

Segundo dato: hace un par de semanas Javier Rodríguez Marcos, en El País, decía que para un autor latinoamericano hoy en día era más fácil ganar el premio Cervantes que encontrar lectores en España.

Tercer dato que quisiera darles y que llega de México: en los inventarios que se han hecho en las distintas librerías del Fondo de Cultura Económica, ahora que hay una transformación, digamos, de la gestión de esa editorial, se han encontrado cientos de libros publicados en Argentina, en Colombia, en Chile, en Venezuela que jamás se vendieron en México. 
Quisiera con estos tres datos comenzar la discusión con ustedes: ¿Qué pasa? ¿En qué estamos hoy? ¿Cuál es la situación de la literatura latinoamericana en Argentina, en Alemania, en Francia? ¿Cómo ven ustedes hoy la presencia de esa literatura desde las localidades de cada uno y a nivel global?

MS: Bueno, la situación actual es pésima. Es deprimente. Uno puede hacer los esfuerzos que se quieran, pero parece como si la literatura contemporánea latinoamericana no pudiese interesar ya a los lectores alemanes. Todos los que estamos trabajando en este campo nos rompemos la cabeza sobre el por qué y cómo se pueda solucionar. Y hasta la fecha no creo que hayamos encontrado argumentos que verdaderamente convenzan. Cuando veo mi trayectoria, cuarenta años trabajando en la edición, he podido publicar en los años 80 y 90 en Suhrkamp diez libros anuales latinoamericanos. Hoy llegamos entre todas las editoriales alemanas, tal vez y con suerte, a diez libros anuales. Y la recepción por supuesto es muy modesta, las cifras de ventas son más que modestas y la crítica ya no tiene un papel importante. Nosotros nos alegramos, como siempre, cuando hay una crítica positiva, y hasta cuando hay una crítica regular, pero la incidencia en la venta de tal libro prácticamente se ha reducido a mínimos.

¿Entonces, a qué se debe todo esto? La atención política hacia América Latina ha menguado muchísimo, los periódicos, la prensa, la televisión, las radios ya no tienen muchos corresponsales fijos, la información es muy aleatoria y, por ello, la cultura sufre los daños colaterales, es decir existe una falta de interés tremenda.

GG: Pienso que hay que contrastar esto, porque la opinión de Javier Rodríguez Marcos, que nos ha hecho reír - yo entiendo perfectamente que hoy sea más fácil en España ganar el premio Cervantes que conseguir lectores- es una opinión que se puede trasladar también aquí a Alemania. Antonio Ortuño está en Berlín, con una beca del DAAD, con la que ha estado también Samanta Schweblin, y dentro de unas semanas, tú me decías, que el Festival Internacional de Literatura de Berlín invita a diez escritores latinoamericanos. 0 sea, que no se puede decir que no haya, por el lado de las instituciones culturales, un esfuerzo para mantener la presencia de esta literatura.

FW: Una palabra en cuanto a lo que dijo Michi, creo que desgraciadamente es totalmente correcto ese análisis, pero creo que, o me parece que lo mismo se aplica a las literaturas italianas, francesas, etc., creo que la situación de la literatura latinoamericana es, como dijiste, una catástrofe, pero no es nada excepcional, desgraciadamente.

IG: En Francia dicen que cualquier director de literatura extranjera tiene a los inversionistas y los grandes directores detrás de ellos. Ahora bueno, paramos un 
poco de comprar, porque la literatura extranjera es una catástrofe, toda la literatura extranjera, salvo uno o dos norteamericanos, incluso para los norteamericanos, porque hay gente que dice: los norteamericanos siempre funcionan, siempre se venden. No es cierto. Yo creo que la política de los flujos tendidos de las librerías hizo mucho daño de forma general a los libros que no tuvieron éxito desde las primeras semanas de su publicación. Entonces después de un mes son sacados. Muchas veces, la dirección comercial de una editorial se dice: este libro no se va a vender, entonces no le vamos a dar su oportunidad y vamos a poner en librerías una cantidad muy reducida. Hay toda esta mecánica económica del libro, que está hecha para los libros muy comerciales, que tienen su suerte desde el primer momento, y los que reclaman más tiempo ya no tienen la suerte de tener visibilidad en librerías . . . Hay que componer con esto, mediante invitaciones en librerías, firmas, o festivales, o reseñas de prensa, y mediante una comunicación muy estrecha con los libreros, porque los libreros hacen mucho también.

FW: Sí, puede ser, también está la dimensión de metas, no coinciden, ¿no? . . . Un ejemplo que acabamos de discutir sería Samanta Schweblin, tiene un prestigio impresionante a nivel mundial, pero en términos de ventas efectivas es una pesadilla. Y esa idea de mecanismo, se dice: jah! Bolaño es una gran cosa y en los Estados Unidos automáticamente se traduce, en ventas en Alemania ese tipo de causalidad no existe, no existe automáticamente, es algo que podría funcionar bajo ciertas circunstancias contingentes, pero no es algo que pasa automáticamente.

LD: Una primera cuestión me parece que tiene que ver con la cantidad y con una cuestión de escala. Ya no existen esas grandes ventas, como las que existían con los autores del boom. Seguir confrontando nuestras expectativas con aquellas míticas ventas ya no es posible; entonces, tenemos que pensar de otra manera. Tampoco vende la literatura argentina en Argentina y en América Latina (sacando casos puntuales: Samanta Schweblin en Argentina, por supuesto vende muy bien). Pero un autor latinoamericano o una autora latinoamericana no necesariamente vende grandes cifras, entonces, en principio creo que, lo que hay que acostumbrarse es a nuevas escalas y hacer que esto funcione, que sean rentables las editoriales, que pervivan en el tiempo con una escala más reducida de lo que era antes.

Por otro lado, hay una segunda cuestión que habría que discutir. Hay un editor británico, Michael Bhaskar, que publicó un libro que se llama La máquina de contenido, donde sostiene: no alcanza con decir que lo que hacemos es publicar libros, sino que, lo que hay que hacer es un montón de cosas para que esos libros lleguen a esos lectores potenciales. No estamos solos en esa tarea, una parte la hacemos los editores, en donde tenemos que buscar alianzas y cómplices, básica- 
mente cómplices del otro lado del Atlántico para conseguir también traducciones, y cómplices también en América Latina, cómplices entre críticos literarios, etc., este es un trabajo de cómplices, básicamente eso es la edición, pura complicidad, y por eso las ferias editoriales siguen siendo tan importantes, porque hay algo del vínculo interpersonal. Y luego necesitamos los apoyos institucionales, empezando por el Estado, que está prácticamente ausente, no solo en Argentina, sino en toda América Latina.

GG: Se acaba de evocar el caso de Samanta Schweblin, que ha sido publicada en casi toda Europa. Samanta tuvo una gran presencia estos últimos dos años dentro de Man Booker Prize, ese gran premio internacional. Este premio de pronto ha hecho visibles no solamente a Samanta, sino también, por ejemplo, a Juan Gabriel Vásquez, que fue finalista, y a Alia Trabucco Zerán, la chilena, que también fue finalista. De modo que uno tiene la impresión, pero ustedes me corregirán, de que la vitrina de la lengua inglesa está como moviendo criterios de valor global que se extiende ahora más allá del inglés, hacia otras áreas lingüísticas. Me pregunto si es así o no. Me lo pregunto con respecto a este premio, pero me lo pregunto también con respecto al lugar que las agencias anglosajonas están tomando dentro de la distribución y venta de derechos de traducción de autores latinoamericanos.

FW: Creo que los éxitos más visibles que tuvimos en Suhrkamp no tuvieron nada que ver con las agencias. Claro, hay un impacto, sin duda, pero en el caso de Suhrkamp no es tan grande. Creo que no son tanto las agencias, son instituciones como New Yorker, New York Times Book Review, algunos premios, Man Booker.

MS: Yo creo que en Europa no necesariamente dependemos de las publicaciones en Estados Unidos para decidir si tal editorial va a comprar a tal autor.

IG: Yo lo dudo también pero digo: Estados Unidos ayuda.

MS: Y claro, algunas figuras como Susan Sontag, cuando ella elogiaba a un autor, sobre todo en aquellos años, fue sin duda importante. Pero hoy ya no existen voces que tengan tanta fuerza, es decir, que no se me ocurre ninguno que tuviese tanto poder como Susan Sontag en su momento; tampoco en Francia como lo tuvo Bernard Pivot con su programa de televisión “Apostrophes”.

GG: ¿Y por qué camino hay que pasar, entonces, hoy para conseguir esto? ¿Cuáles son las vías que ustedes ven hoy por las que se puede mover un autor?

IG: Cuando hay un texto que me gusta, me pongo siempre en contacto con los agentes y lo presento. Sin embargo, el campo español para todas las editoriales 
es secundario, entonces, como traductor voy hacia ellos y les digo "mira, esto es interesante", y les hago un informe de lectura. Y los agentes como María Lynch, por ejemplo, siempre ahora hacen samples en inglés, para seducir a estas personas que no practican el castellano, entonces, después de mi informe de lectura, llega el sample a los editores que trabajan con traductores y eso ayuda mucho a vender el libro.

MS: Una vez que el libro está publicado, entonces ¿qué se puede hacer?, esa es la pregunta que nos ponemos ahora todos. Por una parte tenemos la ilusión del editor que lo ha comprado, que prepara todo el material útil para la prensa, para presentarlo de la mejor manera posible. Luego el libro aterriza en las librerías, ¿qué pasa entonces?, la crítica tiene escasa incidencia y la única manera que todavía puede funcionar un poco, captar la atención del lector, es una publicación casi simultánea de críticas en cuatro o cinco periódicos. Pero los libreros, que antes leían atentamente los suplementos literarios, y a continuación pedían los libros de acuerdo a sus preferencias, esto, digamos, hoy ya no existe. Miran el Perlentaucher en la web, que es muy útil, pero sobre todo miran cuántas estrellas tiene el libro en Amazon y basta.

FW: Menos libros, esfuerzos de concentrarse más en cada uno de los libros que, por ejemplo, nosotros publicamos, necesita un esfuerzo de micro marketing, hay que tratar cada uno de los libros como un start-up, es una retórica un poco agresiva, pero eso es lo que tratamos de hacer en Suhrkamp. Claro, hay esa dimensión de prensa que debería funcionar, también necesitamos cubiertas instagrammables, necesitamos algo que pueda funcionar en varios contextos, es decir, que hay que pensar varios aspectos del libro para promocionarlo. Creo que deberíamos enfocarnos en libros que importan. No se puede tratar de llenar puestos de programas, necesitamos libros con sustancia.

GG: Volviendo a las dinámicas globales, el tema de nuestro coloquio, muchos autores y muchos agentes también miran hoy hacia los Estados Unidos, donde solo el 5\%, un pequeño 5\% de la producción total, es una producción de libros traducidos, mientras que en los países europeos pueden llegar hasta el 30 o el $35 \%$ en algunos casos. Los norteamericanos explican que una de las razones por las cuales no se traducen más libros al inglés es porque el público tiene una resistencia hacia la traducción. Yo quisiera que habláramos de este asunto, es decir, ¿cómo ven ustedes la relación de sus públicos con la traducción?, ¿hay una resistencia?, ¿hay una indiferencia hacia la producción de libros traducidos?, ¿hay un interés en la traducción?

FW: Resistencia tal vez a traducciones mal hechas, pero si existieran libros traducidos por Susanne Lange por ejemplo, no es problema . . . No es una pre- 
gunta de interés, es política cultural, creo que generalmente no hay ese efecto descrito como "Jameson effect", que dice que necesito un modelo narrativo bastante rico y puedes añadir aspectos locales. Es decir, que si la pregunta es resistencia a la traducción, es decir, a culturas diferentes, no creo que haya ese tipo de resistencia. Pero todo depende de cómo está hecha la pieza de literatura.

MS: Yo creo que tanto Francia como Alemania tienen una riquísima tradición de leer libros traducidos, Italia y España también la tienen. Los ingleses siempre pensaron que ellos son los dueños del mundo, y por lo tanto todo el mundo habla y tiene que hablar su lengua. En cambio, ellos no necesitan necesariamente abrirse a los otros. Por lo tanto, cada traducción al inglés se celebra como si fuese algo extraordinario, una maravilla.

LD: En Argentina, en muchos casos, contamos con subsidios que dan en general las embajadas de cada país o instituciones de fomento de la literatura de los diferentes países. En la mayoría de los casos: con la gran excepción de Estados Unidos. Sin embargo, a la hora de elegir a qué libros se les otorga un apoyo económico a la traducción, lo que prima muchas veces son las novedades. Y como nosotros publicamos, sobre todo en ensayo, muchos libros de Suhrkamp, por ejemplo, que no son "novedad" estrictamente hablando, son ensayos filosóficos y demás, bueno eso no es prioritario, evidentemente, en términos de materia de subsidio de traducciones. Por eso, me parece que la única manera de que cada proyecto sea viable sigue siendo cómo pensar una ecuación donde las letras y los números funcionen, por decirlo de alguna manera. También por esto mismo en Eterna Cadencia, desde el comienzo hace diez años y medio, teníamos claro que necesitábamos publicar y distribuir nuestros libros en toda América Latina y en España por muchas razones, una de las razones es en términos de ecuación económica: traducir las clases de Theodor Adorno - que estamos traduciendo en este momento- solamente para Argentina es absolutamente inviable, hacerlo con un alcance regional sí funciona. Por otro lado, este no es el único modo de pensar las traducciones, tan costosas a veces. En muchos casos compartimos traducciones con editoriales amigas y cada uno publica la traducción en su propia edición, o coeditamos, o compartimos sesiones de derecho. Practicamos todas las maneras de asociatividad que se puedan imaginar, inclusive trueque de libros, trueques de derechos, hemos inventado todo lo posible. Debido a las crisis que hemos tenido en Argentina y en América Latina, digamos que no queda más remedio que esta creatividad, de la que no me enorgullezco, sino que es simplemente subsistencia. Pero todavía con España no lo hemos hecho. Hablando de España, sí tengo que decir que es el único lugar donde, por momentos, hay resistencia a las traducciones hechas en Argentina. Nosotros, cuando traducimos, traducimos pensando en 
toda la región, en América Latina, y en España. Eso no significa que inventamos un español neutro, como los dibujos animados que ven mis hijas que hablan una lengua que no existe, que ninguno de nosotros habla, pero sabiendo que no existe ese español neutro, tratamos de traducir no en porteño o rioplatense, sino con respeto a la diversidad del lector. Bueno, aun así cada tanto vienen reseñas del otro lado del Atlántico, que es este lado, quejándose de las traducciones porteñas.

GG: Es más fácil editar ahora que antes, Michi, ¿cómo se hace hoy para tener acceso a ciertas informaciones?

MS: Pues, antes uno viajaba y cargaba luego una maleta llena de libros. Tuvimos que conseguir información de países que no estaban en el circuito inmediato, información que era menos fácil. Por ello tuvimos que comprar los libros físicos, ir a las ferias, y luego ver lo que podíamos hacer. Y claro, siempre hubo una red de amigos, sobre todo con Francia, también con Italia, y nos intercambiábamos información, lo mismo que se hace hoy. Antes, digamos, en este aspecto la vida literaria era un poco más tranquila $\mathrm{y}$, por lo tanto, uno podía darse el lujo de recibir un manuscrito en papel y luego obtener una opción de tres meses que luego se redujo a dos meses y finalmente a uno solo, hasta que todo eso se fue al traste. Ahora ya no hay opción ni nada, es decir, todo llega al mismo momento a todas las editoriales en formato PDF. Con lo cual la presión es muy fuerte.

GG: ¿Y cómo estamos con la circulación de libros, como los de Eterna Cadencia, dentro de la propia América Latina? ¿Cuál es la situación del libro argentino en el continente?

LD: Es difícil, como siempre, por las particularidades de América Latina. Aun así, logramos distribuir en prácticamente todos los países de América Latina. Pero es difícil porque la inestabilidad económica de cada uno de los países hace que los distribuidores o las librerías cierren, quiebren, te dejen con la deuda, se quedan con los libros o los libros llegan muy caros a varios de los países. Chile, por ejemplo, todavía tiene IVA sobre el libro, con lo cual a lo que uno lo exporta, hay que sumarle el 19\%. Los costos de transferencia para recibir el dinero son todavía muy altos, los fletes, las logísticas son malas, los libros se pierden, son caros, entonces es bien complejo. Y, de vuelta, hay ausencia del Estado en facilitar este tipo de circulación. Pese a esto, hay distribuidores, hay librerías que subsisten, y hay muchas de ellas que hacen un gran trabajo. Y, si bien hoy todo el trabajo pareciera que se hace por email, las ferias del libro, Guadalajara, Bogotá, Buenos Aires, Frankfurt, son lugares de encuentro - ¡a 
veces nos encontramos en Frankfurt los latinoamericanos!-; las ferias son esos lugares donde seguir afianzando vínculos.

\section{PREGUNTAS DEL PÚBLICO}

P1: No se ha hablado tanto de los cambios en ese público lector, más de consumidor. Si han notado esos cambios, ¿cómo llegamos a ese público?

FW: Bueno, yo creo que en el caso de la literatura latinoamericana, ya no hay un lector habitual, pero es una pregunta más general, creo que estamos en una competencia muy tensa con otras formas, otros formatos, como Netflix, Amazon Prime, todo eso. Es un desafío, pero francamente en la editorial alemana hay muy poco dinero, es decir, que prácticamente no hay recursos para hacer marketing research, es decir, que el lector, la lectora es una figura prácticamente desconocida para nosotros.

P2: Estamos enfrentados a una generación de estudiantes para la que la literatura ya no sirve para acumular capital simbólico. Eso es el principal problema. Somos muchos de nosotros, tal vez, la última generación de filólogos haciendo filología clásica en las universidades, porque a esas alturas también se nos están extinguiendo los alumnos. Aquí en Alemania tenemos ese sistema de formar profesores de institutos, colegios y lo que pasa ahora es que la literatura ha perdido todo el valor que tal vez tenía en algún momento, por ejemplo lo que sale de la lista de lectura para el bachillerato sobre Argentina es un solo texto, es una novela juvenil torpe. Esa es la única ambición que tienen esos alumnos a esas alturas, y estamos fallando en ese sentido, porque no hay alianzas entre el mundo editorial y el mundo universitario en ese sentido.

LD: Creo que hay dos cuestiones que habría que separar y pensar: o se lee menos, o no se lee lo que queremos. Al menos en Argentina, en América Latina, yo diría que, en España, corríjanme si me equivoco, el género que más está subiendo es el de literatura infantil y juvenil, con lo cual se lee, y cada vez se lee más. No se lee tal vez lo que nosotros queremos, y en todo caso a mí, personalmente, lo que me preocupa en todo caso es la lectura crítica, como se está perdiendo la lectura crítica. Pero en términos de lectura no estamos en un retroceso necesariamente.

GG: Hay un punto que es interesante y es el de la aparición en los años 90 de una literatura infantil y juvenil que ha traído consigo toda una serie de temáticas ... y está ocurriendo, no sé si lo hemos visto muy bien, pero está ocu- 
rriendo, que la nueva generación de escritores, y sobre todo de escritoras latinoamericanas, que está escribiendo hoy, se nutrió de esa literatura que hoy vamos a encontrar en el imaginario colectivo con temas de fantasy, con temas de distopía, temas de horror, temas de ciencia ficción . . . hay toda una serie de temáticas con las que están trabajando las autoras contemporáneas latinoamericanas, que vienen directamente de su formación como lectoras de ciertos géneros. No hay que pedirles que reescriban el boom, porque no están reescribiendo el boom, están reescribiendo en parte esa otra literatura, como lo hace, por ejemplo, Mónica Ojeda, como lo hace Mariana Enríquez, como lo hace la propia Samanta Schweblin, están reescribiendo y dándole otro nivel a unos imaginarios que ellas frecuentaron en un momento de su formación como lectoras a principios de los 90 y fines de los 80 .

P4: Yo creo que hay dos representaciones que son importantes de aclarar por lo que se dijo. En Estados Unidos los big five no publican traducciones de literatura latinoamericana, o lo hacen de manera muy excepcional. Todo el boom de la literatura latinoamericana en inglés viene de las editoriales independientes. La otra cuestión que me llama la atención, quizás lo lanzo como pregunta para ustedes que trabajan en las ediciones, yo creo que hay una suerte de desfase entre lo que se está leyendo en América Latina y lo que se traduce. Voy a mencionar dos nombres porque [inentendible], pero si yo enseñara ahorita un curso de novela latinoamericana contemporánea, dos de los últimos nombres que se me ocurriría poner en esa lista son Rodrigo Fresán y Juan Gabriel Vásquez, que no quiere decir que sean malos escritores, mas no son autores vibrantes como, digamos, Mónica Ojeda, Valeria Luiselli, Rita Indiana, Rodrigo Blanco, Selva Almada. En una de esas hay un problema de escala . . . A lo mejor Suhrkamp, y esto también como pregunta, Suhrkamp o Gallimard necesitan una escala, los editores independientes no necesitan.

LD: Me parece que los premios que se mencionaron, los rankings de bestsellers, etc., son faros para las editoriales grandes, para las mainstream. Las editoriales independientes no estamos mirando (solamente) esos lugares; al contrario, lo digo un poco en broma un poco en serio, si un agente me dice: "el autor que estás leyendo se acaba de ganar . . .”, no me interesa más, lo digo en serio, no es un acto de demagogia, porque sé que automáticamente las grandes editoriales se van a pelear por ese libro y van a pagar un montón de dinero, pero además, porque hay algo con la lengua seguramente en ese libro que no resiste más, digamos, una pérdida de resistencia en la lengua, en la escritura, en la lectura, y a mí personalmente me siguen interesando los libros que tienen una resistencia a ser traducidos, que quiero que sean traducidos pero con una resistencia. 
P6: Para los editores especialmente, ¿qué tanto están ocupando la tecnología en estas traducciones?: libros digitales, audiolibros, creo que el futuro va mucho hacia allá, y entonces quiero saber ¿cómo lo están haciendo?, ¿lo usan o no lo usan?

LD: Te respondo cortito: hacemos E-books y empezamos a hacer audiolibros, pero es muy poco lo que se vende en Argentina y en América Latina. No hay dispositivos, la piratería es más importante que la venta legal . . . es un tema enorme, lo hacemos porque hay que hacerlo, porque seguramente el futuro va por ahí, pero no sabemos.

MS: En Alemania el audio también funciona, y funcionaba divinamente hace un par de años, aunque me parece que últimamente ha bajado un poco. Pero las cifras siguen siendo muy altas y las empresas contratan siempre a locutores o locutoras con gran prestigio. Un libro, digamos, del cual el editor supone que va a tener bastante venta, sale casi simultáneamente en audio, E-book y papel.

GG: Y la batalla por los derechos de audiolibro es importante, porque las ventas han crecido en esa área y la gente ahora escucha muchísimo esos libros. 